\title{
BENEFÍCIOS POR INCAPACIDADE NO REGIME GERAL DE PREVIDÊNCIA SOCIAL
}

\author{
Victor Celso Gimenes Franco Filho
}

Universidade do Oeste Paulista - UNOESTE, Presidente Prudente - SP. E-mail: vcg.victor@gmail.com

\section{RESUMO}

O presente estudo tem por objetivo tecer uma análise sucinta a respeito dos benefícios por incapacidade no Regime Geral de Previdência Social (RGPS). A questão se resume, a saber, as principais diferenças e peculiaridades de cada um destes benefícios. Tal assunto é de interesse de toda sociedade, tendo em vista o grande número de benefícios concedidos diariamente. Para tanto, passa-se a análise dos benefícios por incapacidade, partindo-se inicialmente do estudo do auxílio-doença e da aposentadoria por invalidez através de suas principais características e peculiaridades, observando-se a previsão legal, as hipóteses de concessão e manutenção dos benefícios, a renda mensal inicial, a data de início de cada um deles e os motivos que acarretam a cessação dos mesmos. Por fim, analisa-se o auxílio-acidente, concluindo assim a abordagem conceitual dos benefícios por incapacidade oriundos do Regime Geral de Previdência Social.

Palavras-chave: Seguridade Social. Incapacidade. Benefício. Requisitos. Peculiaridades.

\section{DISABILITY BENEFITS IN THE GENERAL SOCIAL SECURITY SYSTEM}

\begin{abstract}
This study aims to weave a brief analysis regarding disability benefits in the General Social Security System (RGPS). The question boils down, namely, the main differences and peculiarities of each of these benefits. This subject is of interest throughout society, in view of the large number of benefits daily. To do so, pass the analysis of disability benefits, starting from the first study of sickness and disability retirement through its main characteristics and peculiarities, observing the legal provisions, the chances of granting and maintenance of benefits, the initial monthly rent, the date of each and the reasons that lead to the termination thereof. Finally, we analyze the accident assistance, thus completing the conceptual approach of disability benefits arising from the General Social Security System.
\end{abstract}

Keywords: Social Security. Disability. Benefit. Requirements. Peculiarities. 


\section{INTRODUÇÃO}

Os eventos que ocorrem na vida do ser humano, provocando um desajuste nas condições normais de vida, em especial na obtenção dos rendimentos provenientes do trabalho, gerando necessidades a serem atendidas, são denominados "riscos sociais".

Em decorrência dos riscos sociais, tem-se no Regime Geral de Previdência Social a possibilidade de concessão de benefícios que visem à cobertura de infortúnios.

Para o estudo destes benefícios devemos levar em consideração a incapacidade laboral ou econômica, consistente na impossibilidade resultante de uma doença ou enfermidade, de forma total ou parcial, para a prática de atividade profissional.

Deste modo, os benefícios previdenciários concedidos em razão da incapacidade laboral, sendo estes classificados em: auxílio-doença, aposentadoria por invalidez e auxílio-acidente, são objetos de estudo pormenorizados no presente trabalho.

\section{MÉTODOS}

Com o propósito de alcançar os objetivos de estudo traçados, o presente trabalho delimitase e centraliza-se seguindo os métodos dedutivo, histórico e comparativo, além de utilizar técnicas de pesquisa documental e bibliográfica.

\section{RESULTADOS}

Os resultados alcançados com a presente pesquisa foram concretizados obtendo-se a diferenciação e classificação dos benefícios gerados através da incapacidade laboral, distinguindose cada espécie de benefício de maneira ímpar, restando comprovada a diferenciação entre os benefícios que, a princípio, mantêm características semelhantes.

\section{DISCUSSÃO}

\section{Auxílio-doença e aposentadoria por invalidez}

Os benefícios por incapacidade laboral "auxílio-doença" e "aposentadoria por invalidez" estão previstos de forma genérica no artigo 201, inciso I, da Constituição Federal. Entretanto, o auxílio-doença é definido nos artigos 59 a 64 da Lei no 8.213/91 e no Regulamento da Previdência Social (Decreto no 3.048/99) nos artigos 71 a 80 e 337, enquanto a aposentadoria por invalidez possui previsão normativa nos artigos 42 a 47 da Lei de Benefícios (Lei no 8.213/91), bem como nos artigos 43 a 50 do Decreto no 3.048/99. 
A aposentadoria por invalidez ${ }^{1}$ uma vez cumprida, quando for o caso, a carência exigida, será devida ao segurado que, estando ou não em gozo de auxílio-doença, for considerado incapaz e insuscetível de reabilitação para o exercício de atividade que lhe garanta a subsistência. Por sua vez, o auxílio-doença é benefício de prestação pecuniária, não programado, que decorre de incapacidade temporária do segurado para o seu trabalho ou atividade habitual ${ }^{2}$.

Deve-se considerar ainda que, a doença, por si só, não gera direito ao benefício, pois o que garante ao segurado a percepção de tal benefício é a incapacidade laborativa habitual ${ }^{3}$. Sendo assim, apesar das semelhanças entre ambos, a duração da incapacidade, sendo esta total ou parcial, temporária ou definitiva, é que os diferencia.

Importante mencionar-se o fato de que ambos poderão ser de duas espécies distintas, quais sejam: comum ou acidentário.

As principais diferenças entre os de origem comum e os acidentários é a dispensa do requisito carência, a estabilidade provisória ao empregado que só é gerada em caso de auxíliodoença acidentário e ainda a competência para julgamento das lides acidentárias, que será sempre da Justiça dos Estados, conforme o artigo 129 da Lei de Benefícios, enquanto o auxíliodoença ou aposentadoria por invalidez comum compete à Justiça Federal.

Quanto à competência para julgamento mencionada deve-se ainda levar em consideração o verbete da Súmula no 235 do Supremo Tribunal Federal: “É competente para a ação de acidente do trabalho a justiça cível comum, inclusive em segunda instância, ainda que seja parte autarquia seguradora".

Importante mencionar-se ainda quanto às diferenças entre estas espécies de benefícios, o fato de que somente os empregados, o trabalhador avulso e os segurados especiais é que têm direito ao auxílio-doença acidentário, pois somente estes são abrangidos pelo SAT - seguro de acidentes do trabalho (IBRAHIM, 2012, p. 646).

Outra diferença é que o segurado que sofreu acidente do trabalho tem garantia, pelo prazo mínimo de 12 meses, à manutenção do seu contrato de trabalho na empresa, após a cessação do auxílio-doença acidentário, independentemente de percepção de auxílio-acidente, pois esta é uma garantia trabalhista ao acidentado.

\footnotetext{
${ }^{1}$ Segundo Wladimir Novaes Martinez (apud CASTRO E LAZZARI, 2013, p. 739): “Juntamente com o auxílio-doença, a aposentadoria por invalidez é benefício de pagamento continuado, de risco imprevisível, devido à incapacidade presente para o trabalho. É deferida, sobretudo, se o segurado está impossibilitado de trabalhar e insuscetível de reabilitar-se para a atividade garantidora da subsistência. (PBPS, caput do art. 43)".

${ }^{2}$ De acordo com a Súmula no 25, da Advocacia Geral da União, editada em 09/06/2008, o benefício auxílio-doença: “Será concedido auxílio-doença ao segurado considerado temporariamente incapaz para o trabalho ou sua atividade habitual, de forma total ou parcial, atendidos os demais requisitos legais, entendendo-se por incapacidade parcial aquela que permita sua reabilitação para outras atividades laborais".

${ }^{3}$ Nesta esteira, o doutrinador Hermes Arrais Alencar (2009, p. 372) especifica que: “A eclosão de doença, por si só, não caracteriza incapacidade para o trabalho. Ao segurado compete comprovar à perícia médica do INSS não apenas a patologia sofrida, mas sim, e principalmente, a repercussão desta no desempenho das atividades profissionais".
} 
Quanto ao período de carência, o artigo 25, inciso I da Lei 8.213/91 prevê que o período exigido para que o segurado faça jus ao auxílio-doença ou a aposentadoria por invalidez é de 12 (doze) contribuições mensais no RGPS.

Tal período de carência será dispensado em três hipóteses, sendo a primeira delas quando ocorrer acidente de qualquer natureza ou causa ${ }^{4}$, conforme acima mencionado.

Quanto a segunda e terceira hipóteses de dispensa de carência, em obediência ao disposto no artigo 26, inciso II, da Lei de Benefícios, deve-se observar a natureza decorrente de doença profissional ou do trabalho e as hipóteses insculpidas no artigo 151 da Lei de Benefícios. Sendo assim, as doenças profissionais ou do trabalho e as doenças constantes da Portaria Interministerial MPAS/MS n 2.998, de 23/08/2001 (art. 151 da Lei de Benefícios), geram a dispensa do requisito carência.

Em caso de perda da qualidade de segurado, as contribuições anteriores a essa data só serão computadas quando após, nova filiação à Previdência Social, o segurado contar, com no mínimo, um terço (1/3) das contribuições necessárias para concessão do benefício.

Com relação à data do início do benefício (DIB) para o auxílio-doença, ao segurado empregado, será contada a partir do 16ㅇ dia do afastamento da atividade, ou da data do requerimento administrativo, quando entre o afastamento e o pedido decorrerem mais de trinta dias. Já para o segurado empregado doméstico, trabalhador avulso, contribuinte individual, especial e facultativo, a data do início do benefício deve ser considerada deste o início da incapacidade, ou a partir do requerimento administrativo se decorridos trinta dias.

Deve-se considerar ainda, conforme a Lei de Benefícios (Lei no 8.213/91), em seu artigo 63, que "o segurado empregado em gozo de auxílio-doença será considerado pela empresa como licenciado".

Por sua vez, a aposentadoria por invalidez será devida, conforme 0 art. 43 da Lei no 8.213/91, a partir do dia imediato da cessação do auxílio-doença. No mais, caso a incapacidade total e permanente seja detectada na própria perícia médica, tal benefício será devido ao segurado com data de início da mesma forma que previsto para o benefício auxílio-doença.

Deve-se considerar ainda que, a precedência de auxílio-doença não é um requisito para a concessão de aposentadoria por invalidez, pois nos termos do "caput" do art. 42 da Lei 8.213/91 a aposentadoria por invalidez poderá ser concedida ao segurado que estiver ou não em gozo de auxílio-doença.

\footnotetext{
${ }^{4}$ Em relação ao termo acidente de qualquer natureza, o doutrinador Ivan Kertzman (2011, p. 346) assim define: “Entende-se como acidente de qualquer natureza ou causa aquele de origem traumática e por exposição a agentes exógenos que acarrete lesão corporal ou perturbação funcional causadora de perda ou redução permanente ou temporária".
} 
A renda mensal do benefício auxílio-doença, de acordo com o art. 39, do Decreto 3.048/99 e com o art. 61 da Lei 8.213/91, será calculada, aplicando-se, sobre o salário-de-benefício, o percentual de 91\% (noventa e um por cento) do salário-de-benefício.

Conforme Miguel Horvath Júnior (2006, p. 296), “o salário de benefício não será equivalente a cem por cento 'para compensar' o fato de que, durante o auxílio-doença, o segurado não efetiva contribuições para o sistema".

Já para a aposentadoria por invalidez a renda mensal inicial (RMI) consistirá numa renda mensal correspondente a $100 \%$ (cem por cento) do salário-de-benefício, nos termos do art. 39, inciso II do Decreto 3.048/99 e do art. 44 da Lei no 8.213/91.

Por sua vez, o art. 45 da Lei 8.213/91 dispõe que "o valor da aposentadoria por invalidez do segurado que necessitar da assistência permanente de outra pessoa será acrescido de $25 \%$ (vinte e cinco por cento)".

Quanto à preexistência da incapacidade, se esta for alegada como causa para concessão do auxílio-doença, observar-se-á o disposto no art. 59, parágrafo único ${ }^{5}$, da Lei de Benefícios. Ou seja, não será devido auxílio-doença ao segurado que se filiar ao RGPS já sendo portador de doença ou lesão invocada como causa da concessão do benefício, salvo quando a incapacidade sobrevier, por motivo de progressão ou agravamento.

Da mesma maneira, nos termos do art. 42, § 2으, da Lei $8.213 / 91^{6}$, não será devida aposentadoria por invalidez ao segurado já portador da doença ou lesão ao filiar-se ao Regime Geral de Previdência Social.

Sendo assim, por ser a previdência social responsável por garantir aos segurados a proteção contra infortúnios, sendo estes eventos futuros e não programados, a ideia de filiar-se ao RGPS já portador de lesão ou doença que seja usada como causa para concessão do benefício se faz totalmente incabível.

Deve-se levar em consideração que nas hipóteses de progressão ou agravamento da doença ou lesão, após a filiação, e o preenchimento dos requisitos para concessão dos benefícios por incapacidade, eventual incapacidade será coberta pelo INSS.

Os segurados que permanecerem em gozo de auxílio-doença serão obrigados, a qualquer tempo, independentemente de sua idade e sob pena de sofrer as sanções cabíveis como a

\footnotetext{
5 “Art. 59. O auxílio-doença será devido ao segurado que, havendo cumprido, quando for o caso, o período de carência exigido nesta Lei, ficar incapacitado para o seu trabalho ou para a sua atividade habitual por mais de 15 (quinze) dias consecutivos. Parágrafo único. Não será devido auxílio-doença ao segurado que se filiar ao Regime Geral de Previdência Social já portador da doença ou da lesão invocada como causa para o benefício, salvo quando a incapacidade sobrevier por motivo de progressão ou agravamento dessa doença ou lesão".

${ }^{6}$ Art. 42 , §2․ "A doença ou lesão de que o segurado já era portador ao filiar-se ao Regime Geral de Previdência Social não lhe conferirá direito à aposentadoria por invalidez, salvo quando a incapacidade sobrevier por motivo de progressão ou agravamento dessa doença ou lesão".
} 
suspensão do benefício, a se submeterem gratuitamente aos exames médicos a cargo da Previdência Social e a reabilitação profissional.

Do mesmo modo, nos termos do art. 46 do Decreto 3.048/99, ao aposentado por invalidez mantêm-se a obrigação de submeter-se a exame médico, processo de reabilitação e tratamento dispensado gratuitamente, sob pena de suspensão do benefício.

Por sua vez, o auxílio doença será cessado em quatro hipóteses, quais sejam: pela recuperação da capacidade laborativa; pela transformação em outro benefício, seja este aposentadoria por invalidez, ou auxílio-acidente, se restar sequela definitiva que implique na redução da capacidade laborativa; ou pela morte do segurado.

Outro fato que pode determinar a cessação do benefício é a recusa ao processo de reabilitação profissional, como já mencionado, já que o art. 79 do Decreto 3.048/99 prevê expressamente esta hipótese.

Por fim, a aposentadoria por invalidez será cessada sempre que verificada uma das condições legalmente previstas. A primeira delas, e mais comum, refere-se à morte do segurado. De outro modo, o segurado que retornar voluntariamente as atividades laborativas terá seu benefício de aposentadoria por invalidez cessado, de acordo com o art. 46 da Lei no 8.213/91. Contudo, nada impede ainda que o segurado, voltando a exercer suas atividades laborativas, obtenha novamente a aposentadoria por invalidez.

\section{Auxílio-acidente}

O benefício "auxílio-acidente" possui previsão legal no art. 201, § 10 da Constituição Federal, bem como nos art. 86 e 104 da Lei 8.213/91e do Decreto no 3.048/99 respectivamente.

Como requisitos para concessão do benefício, podemos elencar as hipóteses previstas no próprio art. 104 do Decreto no 3.048/99: I - redução da capacidade para o trabalho que habitualmente exercia; II - redução da capacidade para o trabalho que habitualmente exercia e exija maior esforço para o desempenho da mesma atividade que exercia à época do acidente; ou III - impossibilidade de desempenho da atividade que exercia à época do acidente, porém permita o desempenho de outra, após processo de reabilitação profissional, nos casos indicados pela perícia médica do INSS.

Conforme o "caput" do referido artigo, o benefício será devido aos segurados empregado e especial e ao trabalhador avulso. No entanto, não farão jus ao benefício o empregado doméstico, o contribuinte individual e o facultativo. 
Contudo, não cabe a concessão de auxílio-acidente em algumas hipóteses, dentre elas: quando o segurado estiver desempregado, bem como, quando houver danos funcionais ou redução da capacidade funcional sem repercussão na capacidade laborativa ou ainda quando houver mudança de função, mediante readaptação profissional.

O auxílio-acidente é devido em decorrência de acidente de qualquer natureza, pois, a partir do advento da Lei no 9.032, de 28 de abril de 1995, substituiu-se a causa "acidente de trabalho" pela expressão de "acidente de qualquer natureza", que engloba não só os infortúnios laborais, como também os de origem diversa, como os ocorridos nos horários de lazer junto à família e aos amigos".

Para concessão do benefício auxílio-acidente não há exigência de preenchimento do requisito carência, sendo necessária apenas a comprovação da qualidade de segurado no dia do acidente.

De outro modo, o art. 86, $\S 20$, da Lei 8.213/91 estabelece o termo inicial do benefício, sendo este: Art. 86, §2‥ "O auxílio-acidente será devido a partir do dia seguinte ao da cessação do auxílio-doença, independentemente de qualquer remuneração ou rendimento auferido pelo acidentado, vedada sua acumulação com qualquer aposentadoria" (Redação dada pela Lei no 9.528, de 1997).

O benefício tem início a partir do dia seguinte ao da cessação do auxílio-doença, independentemente de qualquer remuneração ou rendimento auferido pelo acidentado, ou, na data da entrada do requerimento (DER), quando não precedido de auxílio-doença.

A partir de 10.11.97, em face da Medida Provisória n. 1.596-14, convertida na Lei n. 9.528, de 10.12.97, é vedada a acumulação do auxílio-acidente com qualquer aposentadoria concedida pelo RGPS.

Apesar da vedação constitucional, prevista no art. 201, §2으, de que nenhum benefício terá valor inferior ao salário mínimo, o Decreto no 3.048/99 em seu art. 42, parágrafo único, elencou benefícios que poderão ter valor inferior ao salário mínimo, como é o caso do auxílio-acidente, corresponde a 50\% (cinquenta por cento) do salário-de-benefício que originou o auxílio-doença, haja vista que tal benefício não é substitutivo de renda, possuindo ainda natureza indenizatória.

Neste sentido, o professor Miguel Horvath Júnior (2006, p. 320) ressalta o fato de que o auxílio-acidente "pode ter valor inferior ao salário mínimo em face de sua natureza indenizatória e não substituidora do salário".

Quanto às formas de cessação do benefício em questão, podemos elencar duas hipóteses previstas em lei. A primeira diz respeito ao óbito do segurado, já a segunda versa sobre a 
inacumulatividade com qualquer espécie de aposentadoria, pois o valor mensal ao auxílioacidente será somado ao salário-de-contribuição.

Importante salientarmos ainda o fato de que, caso seja reativado o auxílio-doença que tenha dado origem ao auxílio-acidente, nos termos do §6 do art. 104 do Decreto no 3.048/99, o benefício ficará suspenso até a cessação do auxílio-doença novamente, quando a partir daí o auxílio-acidente será reativado.

\section{CONCLUSÃO}

Depois de preenchidos os requisitos básicos para concessão dos benefícios previdenciários, o indivíduo passa a fazer parte de tal cobertura, sendo assegurado a ele a garantia contra os infortúnios, inclusive os decorrentes dos riscos sociais como a incapacidade.

Para tanto, criaram-se os benefícios por incapacidade laboral, sendo estes divididos entre auxílio-doença, aposentadoria por invalidez e auxílio-acidente. Essas prestações previdenciárias são devidas quando o ser humano comprovadamente não possuir capacidade laboral para garantir a sua subsistência, devido a um fato gerador que o deixou incapacitado.

Desta análise, conclui-se que a seguridade social é importantíssima para promover o bemestar social e a justiça, sem desigualdades, oferecendo assim meios para a subsistência do ser humano quando este não possuir capacidade para exercer funções que lhe garantam o mínimo necessário, disponibilizando os benefícios debatidos no presente estudo como forma de proteção contra os riscos sociais.

\section{REFERÊNCIAS}

ALENCAR, Hermes Arrais. Benefícios Previdenciários. 4ạ ed. rev. e atual., São Paulo: Liv. e Ed. Universitária de Direito, 2009.

BRASIL. Constituição (1988). Constituição da República Federativa do Brasil. Brasília, DF: Senado, 1988.

BRASIL. Decreto no 3.048 de 06 de maio de 1999. Aprova o regulamento da Previdência Social, e dá outras providências. Brasil: Imprensa Oficial, 1999.

BRASIL. Lei 8.212 de 24 de julho de 1991. Dispõe sobre a Organização da Seguridade Social, institui Plano de Custeio, e dá outras providências. Brasil: Imprensa Oficial, 1991.

BRASIL. Lei $\mathbf{8 . 2 1 3}$ de 24 de julho de 1991. Dispõe sobre os Planos de Benefícios da Previdência Social e dá outras providências. Brasil: Imprensa Oficial, 1991. 
CASTRO, Carlos Alberto Pereira de; LAZZARI, João Batista. Manual de direito previdenciário. 15. ed. São Paulo: LTr, 2013. 1338 p.

HORVATH JÚNIOR, Miguel. Direito previdenciário. 6. ed. São Paulo: Quartier Latin, 2006. 543 p.

IBRAHIM, Fábio Zambitte. Curso de Direito Previdenciário. 17ạ ed., Rio de Janeiro: Impetus, 2012.

KERTZMAN, Ivan. Curso Prático de Direito Previdenciário. 8. ed., São Paulo: JusPodivm, 2011. 